\title{
RESEARCH
}

Open Access

\section{Role of swimming on muscle PGC-1a, FNDC5 mRNA, and assessment of serum omentin, adropin, and irisin in high carbohydrate high fat (HCHF) diet induced obesity in rats}

Ehsan Badawy, Nabila A. El-laithy, Safaa M. Morsy, Magdi N. Ashour, Tahany R. Elias, Mahmoud M. Masoud and Omnia Aly ${ }^{*}$ (D)

\begin{abstract}
Background: Exercise benefits a variety of organ systems in mammals, and some of the best recognized effects of exercise on muscle are mediated by the transcriptional peroxisome proliferator-activated receptor gamma coactivator 1-a (PGC-1a). The regulatory effect of swimming on muscle PGC-1a, FNDC5 mRNA expression, and subsequently irisin levels is more controversial. This study aimed to investigate the role of swimming as an exercise on the expression of peroxisome proliferator-activated receptor-gamma coactivator1 alpha (PGC-1a) and Fibronectin type III domain containing 5 (FNDC5) mRNA in skeletal muscle and assessment of serum omentin, adropin, irisin, and PGC-1a levels in high carbohydrate high fat (HCHF) diet induced obesity in rats. Sixty male albino rats are randomly divided into 4 groups (15 rats/group). In the first group (control), rats are fed with standard diet. The 2nd group (cont + swim) is fed on standard diet and made swimming exercise. The 3rd group of rats is fed on $\mathrm{HCHF}$, whereas in the 4th group ( $\mathrm{HCHF}+$ swim) is also fed on $\mathrm{HCHF}$ diet and made swimming exercise for 20 weeks. Blood glucose, insulin, HOMA-IR, lipid profile, omentin, irisin, adropin, and PGC-1a were measured. Also, FNDC5 and PGC-1a are extracted and purified from muscle tissue samples measured by PCR test.

Results: Our results showed significant increase in glucose, insulin, insulin resistance, cholesterol, and triglycerides with significant decrease in omentin, irisin, adropin, PGC-1a, and HDL in HCHF group as compared to the control group. These results improved after exercise in all parameter in HCHF + swim group compare to HCHF group. Also, there was inverse correlation between omentin and fasting glucose and HOMA-IR in HCHF + swim group.

Conclusions: It concluded that swimming exercise improved all the above measured parameters in serum and tissues which might have been promising for the prevention of metabolic diseases.
\end{abstract}

Keywords: HCHF-diet, Irisin, Adropin, Omentin, PGC-1a, FNDC5

* Correspondence: onnyashraf@live.com

National Research Centre, Department of Medical Biochemistry, Cairo, Egypt

(0) The Author(s). 2020 Open Access This article is licensed under a Creative Commons Attribution 4.0 International License, which permits use, sharing, adaptation, distribution and reproduction in any medium or format, as long as you give appropriate credit to the original author(s) and the source, provide a link to the Creative Commons licence, and indicate if changes were made. The images or other third party material in this article are included in the article's Creative Commons licence, unless indicated otherwise in a credit line to the material. If material is not included in the article's Creative Commons licence and your intended use is not permitted by statutory regulation or exceeds the permitted use, you will need to obtain permission directly from the copyright holder. To view a copy of this licence, visit http://creativecommons.org/licenses/by/4.0/. 


\section{Background}

Exercise is not only an active and preferred way of improving health but also a useful way of reducing the hazard of metabolic diseases [1]. Participation in regular exercises minimizes the incidence of type II diabetes, cardiovascular disease, and obesity and prevents further retrogradation in health [2]. Exercise may enhance shrinkage of musculature as well as encourage secretion of complex muscular parameters [3]. Irisin is a newly discovered myokine which secreted in response to exercise [4]. Skeletal muscle is the main source of irisin production. Irisin has numerous physiological functions including thermogenesis, glucose metabolism, increased metabolism, differentiation, and proliferation [5].

Obesity is a mild systemic inflammatory disease associated with a wide range of diseases such as diabetes, insulin resistance, cardiovascular disease, chronic kidney disease, cancer, and other metabolic syndromes [6]. Adipose tissue (AT) contains adipocytes and stromal vascular cells. Sedentary lifestyles and lack of exercise are the leading causes of obesity and metabolic disorders [7]. As an endocrine organ, AT secretes several adipokines which have broad activities on carbohydrate and lipid metabolism and are implicated in many diseases [8].

Peroxisome proliferator-activated receptor gamma coactivator 1- $\alpha$ (PGC-1 $\alpha)$ and Fibronectin type III domain containing 5 (FNDC5) are the main regulators of irisin synthesis in muscle prior to being released into the circulation. Exercise caused the expression of PGC-1 $\alpha$ in skeletal muscle, encouraging the cleavage of FNDC5 to irisin. Irisin is firstly identified as a PGC- $1 \alpha$ supported myokine with the ability to induce murine brown-fatlike development of white adipose tissue [5].

Omentin is an anti-inflammatory adipocytokine that is abundantly expressed in visceral fat tissue with insulinsensitizing effects. Omentin acts centrally to modulate the insulin resistance, body weight, anti-inflammatory effect [9], activates endothelial nitric oxide synthase [10], and contributes to regulation of lipid metabolism [11].

Omentin levels are decreased in insulin resistant and pro-inflammatory conditions (obesity, diabetes mellitus types I and II) [12].

Adropin is a peptide hormone discovered by Kumar et al. in 2008. It is closely related to the inhibition of atherosclerosis by upregulation of the endothelial nitric oxide synthase expression. Therefore, this peptide is recently identified as an important mediator for energy homeostasis, lipid metabolism, and maintaining insulin sensitivity. Also, it protected against obesity-associated hyper-insulinemia by regulating the lipid and glucose metabolism [13].

High carbohydrate high fat diet in rats prompt the metabolic syndrome symptoms such as hypertension, dyslipidemia, impaired glucose tolerance, excess fat deposition, increased pro-inflammatory markers, and reduced antioxidant defenses [14].

Our aim was to investigate the effect of swimming as exercise in improving levels of PGC-1 $\alpha$ and FNDC5 in skeletal muscle and serum levels of irisin, adropin, omentin, and PGC- $1 \alpha$ in obese rats fed HCHF diet for the prevention of metabolic diseases resulting in obese case.

\section{Methods \\ Materials}

Sixty male albino rats (150-165 g) were obtained from author's institution and were allowed a standard rodent chow diet and water ad libitum. They were housed in standard environmental conditions. The ambient temperature was $25 \pm 2{ }^{\circ} \mathrm{C}$, and the light/dark cycle was 12/12 h. High carbohydrate high fat (HCHF) diet (Western style diet) prepared according to Christopher et al. [15] and was used in this study to induce a model more closely mimics to the changes observed in human obesity. Standard diet was prepared according to Reeves [16]. All animals received human care in compliance with guidelines of the Ethical Committee number 16/ 355 and followed the recommendations of National Institutes of Health Guide for Care and Use of Laboratory Animals.

\section{Experimental design}

Sixty male albino rats were randomly divided into 4 groups (15 rats/group).

In 1st group (control), rats were fed with standard diet.

In 2nd group (control + swimming), rats were fed on standard diet and made swimming exercise, $60 \mathrm{~min} /$ day, 5 days/week for 20 weeks, according to Saleh et al. [17].

In 3rd group (HCHF diet group), rats were fed on $\mathrm{HCHF}$ diet for 20 weeks.

In 4th group (HCHF diet + swimming group), rats were fed on HCHF diet and made swimming exercise (60 $\mathrm{min} /$ day, 5 days/week for 20 weeks).

After the experimental period, animals were fasted overnight before blood sampling. The blood was aspirated under formalin anesthesia from the retro-orbital venous plexus of the eye using capillary tubes, left to clot, and then centrifuged for $15 \mathrm{~min}$ at $3000 \mathrm{rpm}$ using cooling centrifuge (Laborzentrifugen, 2 K15, Sigma, Germany) to obtain serum which stored at $-80{ }^{\circ} \mathrm{C}$ till the day of the evaluation. Muscle biopsies were collected and immediately immersed in RNALater and stored at $80{ }^{\circ} \mathrm{C}$ until gene-expression analyses were conducted.

\section{Biochemical analysis}

\section{Determination of glucose level}

Glucose level in serum was measured according to the methods of Passing and Bablok [18] by standard 
commercial colorimetric enzymatic assays (BioMerieux, Marcy l'Etoile, France; Roche Diagnostics, Basel, Switzerland).

\section{Determination of insulin level}

Serum insulin level was estimated by enzyme-linked immunosorbent assay according to Yallow and Bawman [19] using BioSoure INSEASIA Co. (Nivelles, Belgium) Kit. Insulin resistance was calculated from the following equation:

HOMA-IR formula (homeostatic model assessment for insulin resistance $)=$ fasting insulin $(\mathrm{mUI} / \mathrm{l}) \times$ fasting glucose (mmol/l)/22.5 (Mathews et al.) [20].

\section{Determination of lipid profile level}

Cholesterol, triglycerides (TG), and high density lipoprotein (HDL-cholesterol) serum levels were assessed using standard commercial colorimetric enzymatic assays (BioMerieux, France; Roche Diagnostics, Basel, Switzerland) by Kwang et al. [21], Cole et al. [22], and Lopez-Virella et al. [23], respectively.

\section{Determination of serum levels of omentin, irisin, adropin, and peroxisome proliferator-activated receptor-gamma coactivator1 alpha (PGC-1a)}

The levels of serum omentin, irisin, adropin, and peroxisome proliferator-activated receptor-gamma coactivator1 alpha $(\mathrm{PGC}-1 \alpha)$ were determined using enzyme-linked immunosorbent assay (ELISA) for rat according to De Souza Batista et al. [24], Samy et al. [25], Topuz et al. [26], and Lee et al. [27] respectively using the manufacturers protocols (R\&D systems).

\section{Expression of muscle PGC-1a mRNA and FNDC5 mRNA by reverse transcription-quantitative polymerase chain reaction ( $R T-q P C R)$}

Total RNA from muscles was extracted using TRIzol reagents (Invitrogen, Carlsbad, CA, USA) according to the manufacturer's instructions. After purified and DNase-treated using RNeasy mini Kit (Qiagen, USA), RNA will be quantified spectrophotometrically in a NanoPhotometer (NanoDrop 2000, Implen, Germany). The extracted RNA was reverse transcribed into cDNA using a high capacity RNA to cDNA kit (Applied Biosystems, USA), with incubation at $37^{\circ} \mathrm{C}$ for $1 \mathrm{~h}$ followed by inactivation at $95{ }^{\circ} \mathrm{C}$ for $5 \mathrm{~min}$ and then stored at -20
${ }^{\circ} \mathrm{C}$ till used. Real-time PCR was performed using Quantitect SYBR Green PCR reagents on a Light Cycler Agilent Mx3000P. Primers were purchased from Qiagen Quantitect collection as follows: Fibronectin type III domain containing 5 (FNDC5) (Rn_Fndc5_2_SG QuantiTect Primer Assay, Cat \#QT02383276), peroxisome proliferatoractivated receptor-gamma coactivator1 alpha (PGC-1 $\alpha)$ (Rn_Ppargc1a_1_SG QuantiTect Primer Assay, Cat \#QT00189196), and internal control $\beta$-actin (Rn_Actb_1_ SG QuantiTect Primer Assay, Cat \#QT00193473). Cycling conditions applied were $15 \mathrm{~min}$ at $95^{\circ} \mathrm{C}$, followed by $45 \mathrm{cy}$ cles of $95{ }^{\circ} \mathrm{C}$ for $15 \mathrm{~s}, 60{ }^{\circ} \mathrm{C}$ for $30 \mathrm{~s}$, and $72{ }^{\circ} \mathrm{C}$ for $30 \mathrm{~s}$. The results were analyzed using the $2^{-\Delta \Delta C t}$ method [28], with $\beta$ actin used as the internal reference gene.

\section{Statistical analysis}

All data was stated as mean \pm SEM. The normal distribution of data was confirmed using the normal state test (SPSS package) (version 18). Statistical significance was examined by one way analysis of variance (ANOVA) trailed by post hoc Tukey's tests (experiments with more than two groups and one variable). Pearson's correlation coefficient was obtained. $p$ value $<0.05$ was considered as statistically significant.

\section{Results}

Table 1 shows that there was no significant difference between study groups regarding base line weight. After the experimental period ( 20 weeks), the weight was significantly increased in HCHF diet group compared to control. On the other hand, weight was significantly decreased in HCHF diet + swim group compared to that of HCHF diet group.

Table 2 shows significant increase in glucose, insulin, HOMA-IR, cholesterol, and triglycerides with significant decrease in HDL level in HCHF group as compared to the control; these results improved after exercise in all parameter in HCHF + swim compared to HCHF group.

Table 3 shows a significant decrease in omentin, irisin, adropin, and PGC-1 $\alpha$ in HCHF group when compared to control one. After swimming, there was improvement in omentin, adropin, and PGC- $1 \alpha$ in both control and $\mathrm{HCHF}$ groups comparing to the counterparts groups. In case of irisin, there was significant increase in HCHF + swim group compared to HCHF group, while there was

Table 1 Weight of rats in different studied groups

\begin{tabular}{lllll}
\hline & Control, $\boldsymbol{n}=15$ & Cont + swim, $\boldsymbol{n}=15$ & HCHF, $\boldsymbol{n}=15$ & HCHF + swim, $\boldsymbol{n}=15$ \\
\hline Base line weight $(\mathbf{g m})$ & $97.1 \pm 1.6^{\mathbf{a}}$ & $97.7 \pm 3.7^{\mathbf{a}}$ & $89.5 \pm 6.1^{\mathbf{a}}$ & $101 \pm 11.0^{\mathbf{a}}$ \\
Weight gain (gm) & $145.8 \pm 7.0^{\mathbf{a}}$ & $128 \pm 8.3^{\mathbf{b}}$ & $274 \pm 9.6^{\mathbf{c}}$ & $223 \pm 9.2^{\mathbf{d}}$ \\
$\quad$ \% of weight gain & 49.26 & 31.9 & 206 & 120.79 \\
\hline
\end{tabular}

Values are expressed as mean \pm standard error (SE). $n$ denotes number of rats in each group. Different letters (superscripts $a, b, c, d)$ indicate statistical differences (one-way ANOVA with post hoc Tukey test. A value of $p<0.05$ was considered statistically significant) 
Table 2 Fasting glucose, insulin, HOMA-IR, and lipids profile in different groups

\begin{tabular}{|c|c|c|c|c|}
\hline & Control, $\boldsymbol{n}=15$ & Cont + swim, $\boldsymbol{n}=15$ & $\mathrm{HCHF}, \boldsymbol{n}=15$ & $\mathrm{HCHF}+$ swim, $\boldsymbol{n}=15$ \\
\hline Glucose (mg/dl) & $87.15 \pm 10.6^{\mathbf{a}}$ & $76 \pm 10.1^{a}$ & $163 \pm 7.6^{\mathbf{b}}$ & $116 \pm 4.7^{c}$ \\
\hline Insulin (mUI/I) & $0.73 \pm 0.02^{a}$ & $0.41 \pm 0.02^{\mathbf{b}}$ & $1.03 \pm 0.08^{c}$ & $0.68 \pm 0.04^{a}$ \\
\hline HOMA-IR & $0.15 \pm 0.01^{\mathrm{a}}$ & $0.05 \pm 0.02^{\mathbf{b}}$ & $0.39 \pm 0.03^{c}$ & $0.19 \pm 0.01^{\mathrm{a}}$ \\
\hline Cholesterol (mg/dl) & $57 \pm 9.7^{\mathbf{a}}$ & $48.8 \pm 8.1^{\mathbf{a}}$ & $180 \pm 19.6^{\mathbf{b}}$ & $74.8 \pm 14.1^{c}$ \\
\hline Triglyceride (mg/dl) & $55.8 \pm 17.6^{\mathbf{a}}$ & $31.8 \pm 4.0^{\mathbf{b}}$ & $135 \pm 15.3^{c}$ & $125 \pm 10.4^{c}$ \\
\hline HDL-cholesterol (mg/dl) & $88.5 \pm 0.7^{\mathbf{a}}$ & $104 \pm 4.2^{\mathbf{b}}$ & $57.5 \pm 3.5^{c}$ & $95.5 \pm 3.3^{\mathbf{b}}$ \\
\hline
\end{tabular}

Values are expressed as mean \pm standard error (SE). $n$ denotes number of rats in each group. Different letters (superscripts a, b, $c$, d) indicate statistical differences (one-way ANOVA with post hoc Tukey test. A value of $p<0.05$ was considered statistically significant)

no significant increase in control + swim group when compared to control one.

There was noticeable negative correlation between omentin and fasting glucose and HOMA-IR in HCHF + swim group as shown in Table 4.

In case of rats received standard diet, results revealed that the expression of FNDC5 mRNA in the skeletal muscle of rats performed regular swimming significantly increased comparing to their control counter parts. But, in case of rats that regularly received $\mathrm{HCHF}$ diet, no significant change was detected in the relative expression of FNDC5 mRNA comparing to rats that received standard diet, while the highest significant elevation in the muscle expression of FNDC5 mRNA was shown in $\mathrm{HCHF}+$ swim group compared to other groups (Fig. 1).

In case of rats which received standard diet, results revealed that the expression of muscle PGC- $1 \alpha$ mRNA in rats which performed regular swimming (cont + swim) was significantly increased comparing to control rats group. Interestingly, the highest elevation in the relative expression of PGC- $1 \alpha$ mRNA is found in rats performed regular swimming and fed on $\mathrm{HCHF}$ diet, while in rats that regularly received HCHF diet, no significant change was detected in the expression of PGC- $1 \alpha$ mRNA comparing to rats that received standard diet (Fig. 2).

\section{Discussion}

Many studies were done to reveal the importance of exercise as non-drug protocol which protect from obesity [29-31]. The physiological effects of exercise on adipose tissue could vary depending on the type and amount of exercise. Preceding studies stated that RT (resistance training) and swimming have particularly affected the parameters of body weight, inflammation, and adipocyte areas [32].

The high prevalence of both metabolic syndrome (MS) and obesity was fundamentally due to sedentary lifestyle and over-nutrition. However, the contribution of MS to obesity has involved various factors, including insulin resistance, central obesity, infections, oxidative stress, and genetic predisposition. As MS affects the entire endocrine system, it caused physiological and biochemical abnormalities [33].

With respect to lipid profile, our study showed a significant increase in triglyceride and total cholesterol levels and a significant decrease in HDL-cholesterol in obese group (HCHF diet group) compared to control group. These increases were elucidated as follows: fructose was first converted to fructose 1-phosphate [34] that hydrolysis by fructose-1-phosphate aldolase (aldolase) to form dihydroxyacetone phosphate and then by triosephosphate isomerase encouraging the synthesis of fatty acids, resulting finally in triglyceride synthesis [35].

HOMA-IR has increasingly been identified as a major factor linking MS to obesity. HOMA-IR is associated with excessive fat accumulation in tissues, such as the liver and increased circulation of free fatty acids, which could furthermore promote inflammation and stress of the endoplasmic reticulum. This in turn exacerbates the condition and maintains the vicious insulin-resistant state [9]. In this regard, the present study revealed an increment of the HOMA-IR index in rats receiving $\mathrm{HCHF}$ diet (HCHF group) as compared to control group (0.39 \pm 0.03 vs $0.15 \pm 0.01$, respectively).

Table 3 Serum omentin, irisin, adropin, and PGC-1a in the different studied groups

\begin{tabular}{lllll}
\hline & Control, $\boldsymbol{n}=15$ & Cont + swim, $\boldsymbol{n}=15$ & HCHF, $\boldsymbol{n}=15$ & HCHF + swim, $\boldsymbol{n}=15$ \\
\hline Omentin (ng/ml) & $17.76 \pm 1.14^{\mathbf{a}}$ & $25.2 \pm 1.8^{\mathbf{b}}$ & $5.6 \pm 0.99^{\mathbf{c}}$ & $13.4 \pm 3.4^{\mathbf{d}}$ \\
Irisin (pg/ml) & $22.4 \pm 1.4^{\mathbf{a}}$ & $25 \pm 1.2^{\mathbf{a}}$ & $17.4 \pm 2.0^{\mathbf{b}}$ & $25.7 \pm 3.7^{\mathbf{a}}$ \\
Adropin (pg/ml) & $757 \pm 80.7^{\mathbf{a}}$ & $829 \pm 66^{\mathbf{b}}$ & $628 \pm 44^{\mathbf{c}}$ & $744 \pm 32^{\mathbf{a}}$ \\
PGC-1a (pg/ml) & $267 \pm 66^{\mathbf{a}}$ & $378 \pm 14^{\mathbf{b}}$ & $135 \pm 12^{\mathbf{c}}$ & $219 \pm 24^{\mathbf{d}}$ \\
\hline
\end{tabular}

Values are expressed as mean \pm standard error (SE). $n$ denotes number of rats in each group. Different letters (superscripts $a, b, c$, d) indicate statistical differences (one-way ANOVA with post hoc Tukey test. A value of $p<0.05$ was considered statistically significant) 
Table 4 Correlations between omentin with fasting glucose and HOMA-IR in HCHF + swim group

\begin{tabular}{llll}
\hline & & Fasting glucose & HOMA-IR \\
\hline Omentin (ng/ml) & Pearson correlation & $-0.847^{*}$ & $-0.794^{*}$ \\
& Sig. (2-tailed) & 0.016 & 0.033 \\
\hline
\end{tabular}

Pearson's correlation coefficient was obtained. $p$ value $<0.05$ was considered as statistically significant

*Connection is significant at the 0.05 level (2-tailed)

Omentin is widely involved in a variety of pathophysiological processes such as obesity, insulin resistance, inflammatory response, atherogenesis, and regulation of vascular endothelial function [36]. Zengi et al. [12] has been observed that levels of omentin were reduced in insulin-resistant and pro-inflammatory conditions (obesity and diabetes mellitus types I and II). Saremi et al. [37] and Wilms et al. [38] showed that aerobic training (AT) increased the concentration of omentin. Alizdeh et al. [29] showed that omentin gene expression is increased significantly after 8 weeks of high-intensity interval-exercise (HIIE), where the omentin concentration in rats $(\mathrm{HCHF}+$ swim) group was increased significantly compared with rats in the HCHF group. Regarding obesity, Auguet et al. [39] and Goodarzi et al. [40] reported a pathological significant decrease of omentin level in obese women than in normal weight women. Also, Escoté et al. [41] have been reported that obesity reduced omentin serum concentration and excretion of adipose tissue in adults and adolescents. Elsaid et al. [42] also reported a significant low level of serum omentin in obese type II diabetic females in comparison to healthy subjects.

Saremi et al. [37] noted that participants with average weight had higher serum omentin concentrations than participants who were overweight and obese, and there was an inverse association between omentin, fasting glucose, and insulin resistance, and these results are in consistent with our results (Table 3). These results suggested that exercise-induced change in omentin might be associated with the beneficial effects of exercise on insulin sensitivity and weight reduction. In addition, De Castro et al. [32] have been reported that aerobic training (AT) affects the glucose pathway by stimulating phosphorylation of protein kinase in muscle tissue. In agreement with previous studies, the present research observed a significant rise in the mean serum level of omentin in rats practice swimming as shown in control + swim and HCHF + swim groups compared to control group and HCHF diet group, respectively. The longterm regulation of the expression of omentin could have been indicated in parallel with decreased insulin resistance and improvement in glucose level, so serum omentin could be used as a vital sign of obesity-related metabolic disorders.

Many lines of evidence were compatible with the notion that PGC-1 $\alpha$ functioned in enhancing skeletal muscle oxidative ability. Over expression of PGC- $1 \alpha$ in cultured myoblasts increased mitochondrial biogenesis and oxidative respiration [43]. Exercise or muscle contractions stimulated PGC- $1 \alpha$ transcription in skeletal muscle through activation of the p38 MAPK pathway [44], where the p38 MAPK pathway in skeletal muscle was essential for myogenic cell differentiation and played an important role in the metabolism of glucose and expenditure of energy [45, 46]. Our results were in agreement with the previous authors, where this study revealed the serum levels PGC- $1 \alpha$ increased in rats fed on standard diet in comparison with rats fed HCHF diet as shown in Table 3 as well as the relative expression of skeletal muscle PGC- $1 \alpha$ mRNA in were increased significantly after swimming sessions (Fig. 2), as compared to sedentary control rats.

Irisin was first described as a PGC- $1 \alpha$-dependent myokine capable of generating brown-fat murine growth of white fat tissues [47]. Also, Norheim et al. [48] reported that the regulating impact of practice on the muscular expression of FNDC5 mRNA and consequently irisin

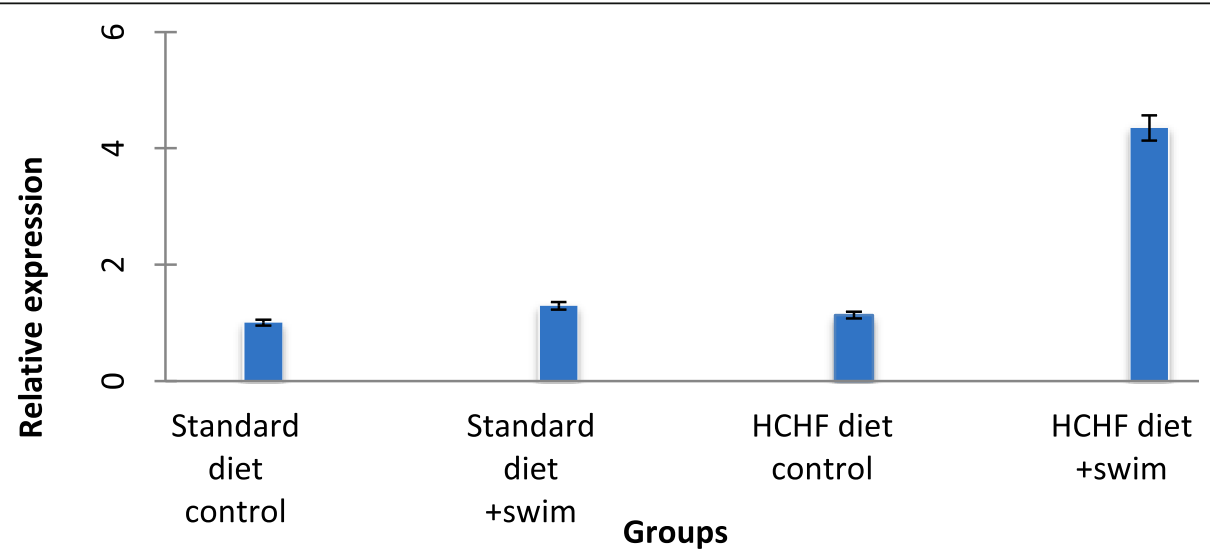

Fig. 1 Relative fold change of muscle FNDC5 mRNA expression in different studied groups 


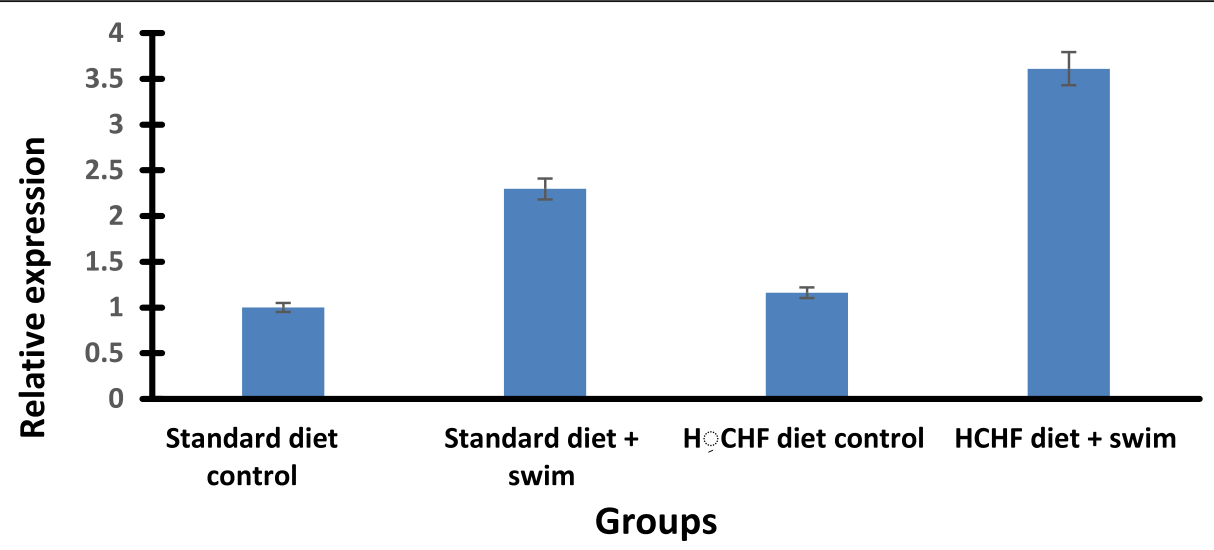

Fig. 2 Relative fold change of muscle PGC-1a mRNA expression in different studied groups

levels in plasma was more ambiguous in humans. Nevertheless, Timmons et al. [49] study was attacked for embedding physical activity without inducing expression of PGC-1 $\alpha$ in the muscle. Timmons et al. [49] demonstrated muscle activation of the FNDC5 in old, but not young, extremely active individuals. In current study, significant increase in the relative expression of levels of PGC- $1 \alpha$ and FNDC5 mRNA in rats practice swimming as compared to sedentary rats served as control was observed as shown in Figs. 1 and 2. Lecker et al. [50] and Pang et al. [51] supported the importance of PGC- $1 \alpha$ as a transcription regulator of FNDC5. Tiano et al. [52] suggested that exercise could increase irisin excretion by raising the expression and activating PGC- $1 \alpha$ and FNDC5. In fact, these findings indicate that combined expression of FNDC5 and PGC- $1 \alpha$ can help to increase and/or sustain levels of plasma irisin after exercises. In our study, as in Figs. 1 and 2, the highest FNDC5 and PGC- $1 \alpha$ levels were highly noticeable after swimming sessions but are followed by a minute increment in irisin levels; this observation might be due to the time of sample collection, where blood sample was taken $24 \mathrm{~h}$ after the last swimming session. In this regard, Pang et al. [51] postulated that the levels of plasma irisin elevated by $6 \mathrm{~h}$ to reach the maximum values and then reduced to $24 \mathrm{~h}$ control levels after an hour of exercises, where expression rates of FNDC5 and PGC- $1 \alpha$ mRNA increased by $12 \mathrm{~h}$ and stayed at high levels through $24 \mathrm{~h}$.

In our study, the serum irisin level was the lowest in the HCHF diet group, indicating that high-carbohydraterich diet diminished the levels of serum irisin, while swimming exercise raised its values (Table 4). These findings are in accordance with $\mathrm{Lu}$ et al. [53] who have shown that irisin may play a particular role in improving fat metabolism through exercise, suggesting that irisin has increased fat tissue energy consumption.

Adropin has been identified as a fixed secretory protein containing 76 amino acids which is encoded by a protein by a gene associated with protein energy balance (Enho). Adropin is expressed in the liver, brain, umbilical vein, and endothelial cells in the coronary artery [54].

Aerobic exercise training raised the amount of serum adropin and enhanced arterial rigidity and adiposity in obese adults. Mechanism of the beneficial effects of adropin on the function of endothelial has suggested that serum adropin promoted nitric oxide production and increased bioavailability of nitric oxide which improved arterial stiffness [55]. These findings suggested that serum adropin has a potential mechanism underlying improved endothelial function caused by aerobic exercise. In agreement with previous studies, the present study showed a significant rise in average serum level of adropin of swimming practice rats as shown in cont + swim and HCHF + swim groups, $60 \mathrm{~min} / 24 \mathrm{~h}$ and 5 days/week for 20 weeks (Table 3), which could indicate a long-term regulation of adropin expression in parallel with a decrease in HOMA-IR and improvement in glucose level, so serum adropin could be also used as a vital indicator of metabolic disorders associated with obesity.

\section{Conclusion}

In conclusion, our data suggested that obesity is mainly associated with fatty liver and HOMA-IR arising from intake of diet having high carbohydrate high fat contents could cause a significant decrease in the myokines and adipokines involved in the metabolic process of food contents. In this regard, chronic swimming causes a general improvement that mimics the action of irisin. Accordingly, this study suggested the organizational link between FNDC5 and PGC- $1 \alpha$ expression that might contribute to achieving appropriate levels of serum irisin after exercise. An increase in circulating omentin has also been observed after a chronic swimming exercise that indicated that 
omentin's ability to reduce HOMA-IR in conjunction with its anti-inflammatory and anti-arterial properties, making it another promising therapeutic target. Thus, omentin might have a beneficial effect on metabolic syndrome and could be used as a biological marker and/or as a drug agent/target in this regard.

\section{Abbreviations}

AT: Adipose tissue; ELISA: Enzyme-linked immunosorbent assay; eNOS: Endothelial nitric oxide synthase; FNDC5: Fibronectin type III domain containing 5; HCHF: High carbohydrate high fat; HDL: High density lipoprotein; HIIE: High-intensity interval-exercise; Iris: Irisin; mRNA: Messenge ribonucleic acid; MS: Metabolic syndrome; PGC-1a: Peroxisome proliferatoractivated receptor-gamma coactivator1 alpha; RT: Resistance training; RTPCR: Real-time polymerase chain reaction; SE: Standard error; SPSS: Statistical package for the social science; TG: Triglycerides

\section{Acknowledgements}

The authors are grateful to the National Research Centre-Cairo, Egypt, for providing space to carry out this work.

\section{Authors' contributions}

MNA and TRE put the design of this study. SMM, OA, and MM carry out the experimental and practical parts. EB and NAE contributed in the interpretation of the data. All participated in the manuscript writing and revision. And finally, all authors have read and approved the manuscript.

\section{Funding}

Project number 11010131 was funded by National Research Centre.

\section{Availability of data and materials}

All data generated or analyzed during this study are included in this published article.

\section{Ethics approval and consent to participate}

All experimental protocols were approved by Ethics Committee of the National Research Centre number 16/355.

Consent to participate is not applicable (experimental model).

\section{Consent for publication}

All the authors listed in this article have approved the final version to be published.

\section{Competing interests}

There are no competing interests.

Received: 17 April 2020 Accepted: 3 July 2020

Published online: 15 September 2020

\section{References}

1. Smith BW, Adams LA (2011) Nonalcoholic fatty liver disease and diabetes mellitus: pathogenesis and treatment. Nat. Rev. Endocrinol 10;7(8): 456-65.

2. Silveira LS, Pimentel GD, Souza CO, Biondo LA, Teixeira AAS, Lima EA et al (2017) Effect of an acute moderate-exercise session on metabolic and inflammatory profile of. PPAR-a knockout mice: Cell Biochem Funct 35(8): 510-517

3. Pratesi A, Tarantini F, Di Bari M (2013) Skeletal muscle: anendocrine organ. Clin Cases Miner Bone Metab 10(1):11-14

4. Huh JY, Mougios V, Kabasakalis A, Fatouros I, Siopi A, Douroudos II et al (2014) Exercise-induced irisin secretion is independent of age or fitness level and increased irisin may directly modulate muscle metabolism through AMPK activation. J Clin Endocrinol Metab 99(11):E2154-E2161

5. Rabiee F, Lachinani L, Ghaedi S, Nasr-Esfahani MH, Megraw TL, Ghaedi K (2020) New insights into the cellular activities of Fndc5//risin and its signaling pathways. Cell Biosci 30(10):51

6. Chait A, den Hartigh $L J(2020)$ Adipose tissue distribution, inflammation and its metabolic consequences, including diabetes and cardiovascular disease. Front. Cardiovasc. Med. 7:22
7. Thompson D, Karpe F, Lafontan M, Frayn K (2012) Physical activity and exercise in the regulation of human adipose tissue physiology. Physiol Rev 92(1):157-191

8. De Flines J, Scheen AJ (2010) Management of metabolic syndrome and associated cardiovascular risk factors. Acta Gastroenterol Belg 73(2):261-266

9. Conway B, Miller RG, Costacou T, Fried L, Kelsey S, Evans RW et al (2010) Temporal patterns in overweight and obesity in type 1 diabetes. Diabet Med 27(4):398-404

10. Chen H, Montagnani M, Funahashi T, Shimomura I, Quon MJ (2003) Adiponectin stimulates production of nitric oxide in vascular endothelial cells. J Biol Chem 7;278(45):45021-26.

11. Yang RZ, Lee MJ, Hu H, Pray J, Wu HB, Hansen BC et al (2006) Identification of omentin as a novel depot-specific adipokine in human adipose tissue: possible role in modulating insulin action. Am J Physiol Endocrinol Metab 290(6):E1253-E1261

12. Zengi S, Zengi O, Kirankaya A, Kucuk SH, Kutanis EE, Yigit O (2019) Serum omentin-1 levels in obese children. J Pediatr Endocrinol Metab 26;32(3):247-51

13. Kumar GK, Zhang J, Gao S, Rossi J, McGuinness OP, Halem HH et al (2012) Adropin deficiency is associated with increased adiposity and insulin resistance. Obesity (Silver Spring) 20(7):1394-1402

14. Schaalan M, El-Abhar HS, Barakat M, El-Denshary ES (2009) Westernized-likediet-fed rats: effect on glucose homeostasis, lipid profile, and adipocyte hormones and their modulation by rosiglitazone and glimepiride. Diabetes Complications 23(3):199-208

15. Christopher RW, Mai KT, Katrina LS, Martin EY, Heinrich A (2007) Western diet, but not high fat diet, causes derangements of fatty acid metabolism and contractile dysfunction in the heart of Wistar rats: Biochem. J 406:457-467

16. Reeves PG (1997) Components of the AIN-93 diets as improvements in the AIN-76A diet. J Nutr 27(5 suppl): $838 \mathrm{~s}-41 \mathrm{~s}$.

17. Saleh BO, Majeed MJ, Oreaby GM (2014) Irisin impact as a medication that ameliorate and hinder the development of insulin resistance associated disorders without regular exercise (experimental study). IOSR Journal of Dental and Medical Sciences 13(9):28-35

18. Passing H, Bablok W (1983) New biochemical procedure for testing the equality of measurements from two different analytical methods. J Clin Chem Clin Biochem 21(11):709-720

19. Yalow R, Bauman WA (1983) Insulin in health and disease. In: Ellenberg M, Rifkin $\mathrm{H}$ (eds) Diabetes mellitus: theory and practice. ExcerptaMedica, New York, pp 119-150

20. Mathews DR, Hosker JP, Rudenski AS, Naylor BA, Treacher DF, Turner RC (1985) Homeostasis model assessment: insulin resistance and $\beta$-cell function fromfasting plasma glucose and insulin concentrations in man. Diabetologia 28(7):412-419

21. Kwang O, Young A (2007) Hyesung L. Isoflavone rich bean sprout cookie improves lipid metabolism in hyperlipidemic rat: The FASEB Journal I 21: 846-848

22. Cole TG, Kuisk I, Patsch W (1984) Schonfeld G. Effects of high cholesterol diets on rat plasma lipoproteins and lipoprotein cell interactions: Lipid Res 25:593-603

23. Lopez-Virella MF, Stone P, Ellis S, Colwell JA (1977) Cholesterol determination in high-density lipoproteins separated by three different methods. Clin Chem 23(5):882-884

24. De Souza Batista CM, Yang RZ, Lee MJ, Glynn NM, Yu DZ, Pray J et al (2007) Omentin plasma levels and gene expression are decreased in obesity. Diabetes 56(6):1655-1661

25. Samy DM, Ismail CA, Nassra RA (2015) Circulating irisin concentrations in rat models of thyroid dysfunction - effect of exercise. Metabolism 64(7):804-813

26. Topuz M, Celik A, Aslantas T, Demir AK, Aydin S, Aydin S (2013) Plasma adropin levels predict endothelial dysfunction like flow-mediated dilatation in patients with type 2 diabetes mellitus. J Investig Med 61(8):1161-1164

27. Lee W, Ham J, Kwon HC, Kim YK, Kim SN (2013) Anti-diabetic effect of amorphastilbol through PPARa/ $/$ dual activation in $\mathrm{db} / \mathrm{db}$ mice: Biochem Biophys Res Commun 1; 432 1)):73- 9

28. Schmittgen TD, Livak KJ (2008) Analyzing real-time PCR data by the comparative CT method. Nature Protocols. 3(6):1101-1108

29. Alizadeh M, Asad MR, Faramarzi M, Afroundeh R (2017) Effect of eight-week high intensity interval training on omentin-1 gene expression and insulinresistance in diabetic male rats. Annals of Applied Sport Science 5(2):29-36 
30. AminiLari Z, Fararouei $M$, Amanat S, Sinaei E, Dianatinasab S, AminiLari M et al (2017) The effect of 12 weeks aerobic, resistance, and combined exercises on omentin-1 levels and insulin resistance among type 2 diabetic middle-aged women. Diabetes Metab J. 41(3):205-212

31. García-Hermoso A, Ceballos-Ceballos RJ, Poblete-Aro CE, Hackney AC, Mota J, Ramírez-Vélez R (2017) Exercise, adipokines and pediatric obesity: a metaanalysis of randomized controlled trials. Int J Obes (Lond) 41(4):475-482

32. De Castro CA, da Silva KA, Rocha MC, Sene-Fiorese M, Nonaka KO, Malavazi I, et al (2019) Exercise and omentin: their role in the crosstalk between muscle and adipose tissues in type2 diabetes mellitus rat models. Front Physiol 7;9:1881

33. Gustafsson D, Unwin R (2013) The pathophysiology of hyperuricaemia and its possible relationship to cardiovascular disease, morbidity and mortality. BMC Nephrol 29;14:164.

34. Mayes PA (1993) Intermediary metabolism of fructose. Am J Clin Nutr 58(5): 754-765

35. Bray GA (2008) Fructose: should we worry? Int J Obes (Lond) 32 Suppl 7: S127-31.

36. Tan BK, Pua S, Syed F, Lewandowski KC, O'Hare JP, Randeva HS (2008) Decreased plasma omentin-1 levels in diabetes mellitus type 1. Diabet Med 25(10):1254-1255

37. Saremi A, Asghari M, Ghorbani A (2010) Effects of aerobic training on serum omentin-1 and cardiometabolic risk factors in overweight and obese men. J Sports Sci 28(9):993-998

38. Wilms B, Ernst B, Gerig R, Schultes B (2015) Plasma omentin-1 levels are related to exercise performance in obese women and increase upon aerobic endurance training. Exp Clin Endocrinol Diabetes 123(3):187-192

39. Auguet T, Quintero Y, Riesco D, Morancho B, Terra X, Crescenti A, et al (2011) New adipokines vaspin and omentin. Circulating levels and gene expression in adipose tissuefrom morbidly obese women. BMC Med Genet 28;12:60.

40. Goodarzi G, Shirgir A, Alavi S, Khoshi A (2019) Effect of insulin-glucose metabolism compared with obesity on adipose omentin gene expression in different models of diabetic C57BL/6 mice. Diabetol Metab Syndr 14;11:65.

41. Escoté X, Gómez-Zorita S, López-Yoldi M, Milton-Laskibar I, FernándezQuintela A, Martínez JA, et al (2017) Role of omentin, vaspin, cardiotrophin1, TWEAK and NOV/CCN3 in obesity and diabetes development. Int J Mol Sci 15;18(8). pii: E1770.

42. Elsaid NH, Sadik NA, Ahmed NR, Fayez SE, Mohammed NAE (2018) Serum omentin-1 levels in type 2 diabetic obese women in relation toglycemic control, insulin resistance and metabolic parameters . J Clin Transl Endocrinol 31;13:14-19.

43. Terada S, Tabata I (2004) Effects of acute bouts of running and swimming exercise on PGC-1alpha protein expression in rat epitrochlearis and soleus muscle. Am J Physiol Endocrinol Metab 286(2):E208-E216

44. Akimoto T, Pohnert SC, Li P, Zhang M, Gumbs C, Rosenberg PB, et al (2005) Exercise stimulates Pgc-1alpha transcription in skeletal muscle through activation of the p38 MAPK pathway. J Biol Chem 20;280(20):19587-93.

45. Zetser A, Gredinger E, Bengal E (1999) p38 mitogen-activated protein kinase pathway promotes skeletal muscle differentiation. Participation of the Mef2c transcription factor. J Biol Chem 19:274(8):5193-200.

46. Yan Z (2009) Exercise, PGC-1alpha, and metabolic adaptation in skeletal muscle. Appl Physiol Nutr Metab 34(3):424-427

47. Boström P, Wu J, Jedrychowski MP, Korde A, Ye L, Lo JC, et al (2012) A PGC1-a-dependent myokine that drives brown-fat-like development of white fat andthermogenesis. Nature 11;481(7382):463-8.

48. Norheim F, Langleite TM, Hjorth M, Holen T, Kielland A, Stadheim HK et al (2014) The effects of acute and chronic exercise on PGC-1alpha, irisin and browning of subcutaneous adipose tissue in humans. FEBS Journal 281(30): 739-749

49. Timmons JA, Baar K, Davidsen PK,Atherton PJ (2012) Is irisin a human exercise gene? Nature 30;488(7413):E9-10; discussion E10-1.

50. Lecker SH, Zavin A, Cao P, Arena R, Allsup K, Daniels KM et al (2012) Expression of the irisin precursor FNDC5 in skeletal muscle correlates with aerobic exercise performance in patients with heart failure. Circ Heart Fail 5(6):812-818

51. Pang M, Yang J, Rao J, Wang H, Zhang J, Wang S et al (2018) Timedependent changes in increased levels of plasma irisin and muscle PGC-1a and FNDC5 after exercise in mice. Tohoku J Exp Med 244(2):93-103

52. Tiano JP, Springer DA, Rane SG (2015) SMAD3 negatively regulates serum irisin and skeletal muscle FNDC5 and peroxisome proliferator- activated receptor $\gamma$ coactivator 1-a (PGC-1a) during exercise. J Biol Chem 1:290(18):11431.

53. Lu Y, Li H, Shen SW, Shen ZH, Xu M, Yang CJ, et al (2016) Swimming exercise increases serum irisin level and reduces body fat mass in high fatdiet fed Wistar rats. Lipids Health Dis 13;15:93.

54. Kumar KG, Trevaskis JL, Lam DD, Sutton GM, Koza RA, Chouljenko VN et al (2008) Identification of adropin as a secreted factor linking dietary macronutrient intake with energy homeostasis and lipid metabolism. Cell Metab 8(6):468-481

55. Fujie S, Hasegawa N, Kurihara T, Sanada K, Hamaoka T, lemitsu M (2017) Association between aerobic exercise training effects of serum adropin level, arterial stiffness, and adiposity in obese elderly adults. Appl Physiol Nutr Metab 42(1):8-14

\section{Publisher's Note}

Springer Nature remains neutral with regard to jurisdictional claims in published maps and institutional affiliations.

\section{Submit your manuscript to a SpringerOpen ${ }^{\circ}$ journal and benefit from:}

- Convenient online submission

- Rigorous peer review

- Open access: articles freely available online

- High visibility within the field

- Retaining the copyright to your article

Submit your next manuscript at $>$ springeropen.com 